\title{
Research on Advantaged Discipline Group of Green Steel Intelligent Equipment and System
}

\author{
Zhao-hui WANG ${ }^{1 *}$, Liang-cai ZENG ${ }^{1}$, Zhen $\mathrm{YU}^{2}$ \\ ${ }^{1}$ College of Machinery and Automation, Wuhan University of Science and Technology, Wuhan, China \\ ${ }^{2}$ National Demonstration Center for Experimental Mechanical Education, Wuhan University of Science and \\ Technology, Wuhan, China \\ Email: zhwang@wust.edu.cn
}

\begin{abstract}
The main focus of intelligent manufacturing and the full implementation of green manufacturing are the strategic focus with development of manufacturing industry. Relying on development action plan of iron and steel industry and advantaged discipline group construction for building double-class, double-service and double-promotion, the advantaged discipline group of green steel intelligent equipment and systems is constructed. According to the eight research directions, the research field, the advantage characteristic and the construction system of the discipline group, the construction contents and the main measures of the advantaged discipline group are analyzed deeply.
\end{abstract}

Keywords: advantaged discipline group, green steel intelligent equipment and system, intelligent manufacturing, green manufacturing

\section{Introduction}

A major strategic deployment was made by the Chinese government to comprehensively improve the quality and level of China's manufacturing industry development based on the general trend of international industrial change in the new international and domestic environment (2015). At the same time, in order to promote the transformation and upgrading of iron and steel industry and enhance the comprehensive competitiveness of iron and steel enterprises, the Ministry of industry and information technology drafted and prepared the action plan for transformation and development of iron and steel industry. The construction of discipline group is guided by the two needs of serving the reform and development of colleges and universities and the economic and social needs, promoting the construction of first-class universities and disciplines, comprehensively improving the ability of colleges and universities to serve personnel training and economic and social development (2011), and vigorously promoting the comprehensive reform of Graduate Education. In view of the current situation and trend of the development of China's machinery manufacturing industry, how to make use of major national industrial policies and build a group of advantageous and characteristic disciplines relying on the iron and steel industry is an urgent problem to be solved in this paper.

\section{The Functional Orientation of the Construction of Advantageous and Characteristic Subject Groups}

As the undertaker of major scientific research projects, the producer of innovative achievements, the training base of innovative talents, the key to the establishment of a world-class university, the concentrated embodiment of the status and level of the University, and the vitality and vitality of the development of the University (YANG Zai-ming, 2008). Therefore, if colleges and universities want to continuously innovate theoretical research, enhance their participation in national major affairs decision-making, and improve their international reputation, they must first cultivate and develop their own advantageous and characteristic subject groups (MA Jian, 2011). As shown in Figure 1, it is the functional positioning diagram of the construction of the advantageous characteristic discipline group. 


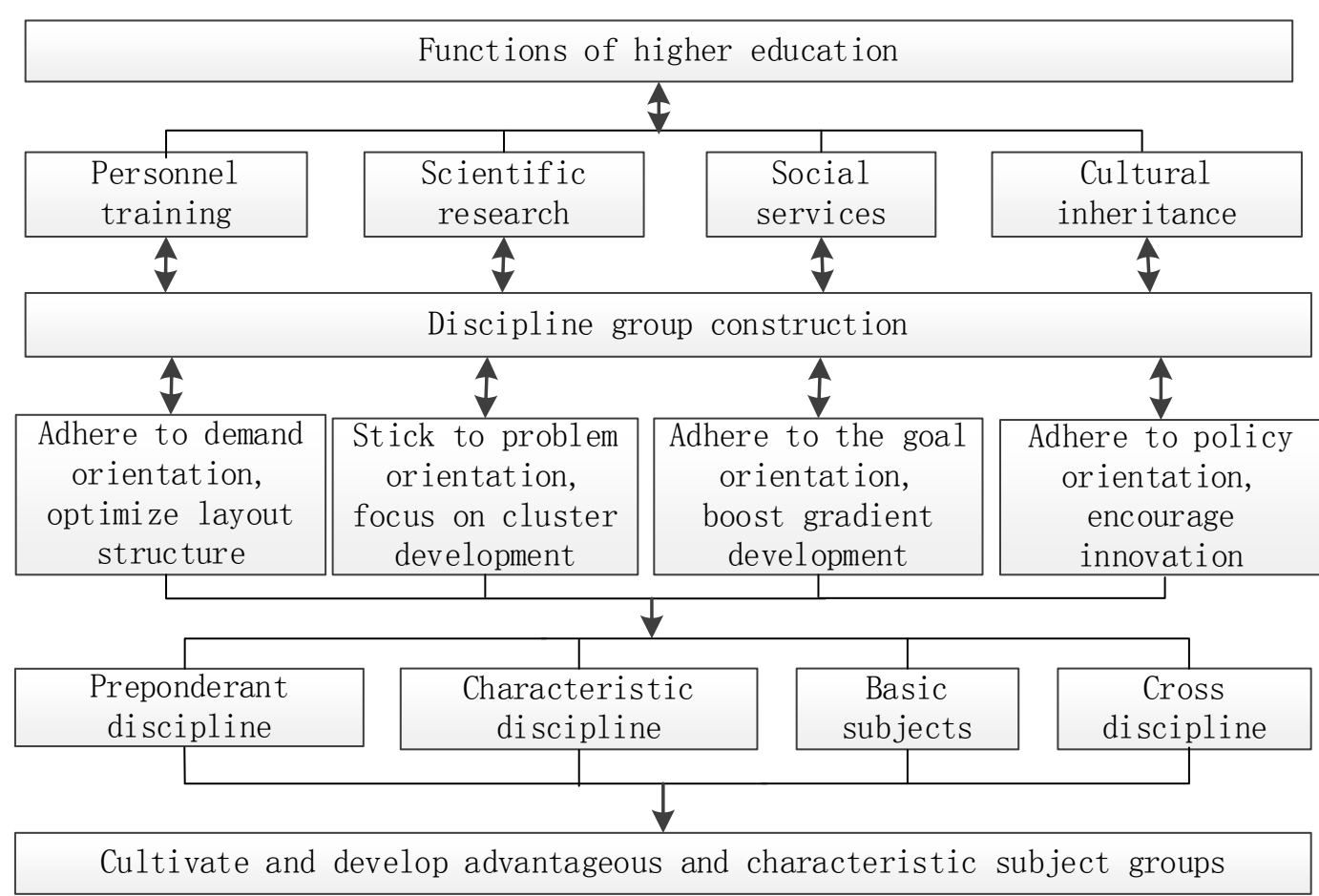

Figure 1. The functional orientation of the construction of advantageous and characteristic subject groups

It can be seen that the number of characteristic disciplines and the degree of correlation between them directly determine the scale of the group. In the process of the transformation from single discipline to multidiscipline, the group of characteristic disciplines also presents the trend of transformation from single discipline to multidiscipline. We should adhere to the demand orientation, optimize the layout structure, and gradually realize the discipline group pattern of integration of preproduction and post production, leading by national key disciplines, relying on provincial key disciplines, and supporting by school level key disciplines. We should adhere to the problem orientation, focus on cluster development, and closely focus on national major industrial needs and major issues, so as to promote the development of advantageous and characteristic disciplines It is necessary to build a multi-level discipline system with comprehensive coverage, reasonable structure and clear levels, adhere to policy orientation, encourage innovation and excellence, and attach great importance to the introduction and training of high-level talents. In recent years, cloud computing, big data, mobile Internet, Internet of things, artificial intelligence and other new generation of information technology have made breakthrough development. Together with manufacturing industry and industrial transformation, it has brought a new technological revolution and industrial revolution to the global manufacturing industry, and provided the best opportunity for the rapid development, transformation and upgrading of China's manufacturing industry(ZHOU Hai-yin, 2015), (LI Tuo-yu, LI Fei \& LU Guo-dong, 2015).

\section{The Advantaged Discipline Group for Manufacturing Industry}

Both the action plan for transformation and development of iron and steel industry have two important strategic priorities: promoting the deep integration of informatization and industrialization, including accelerating the integration of new generation information technology and manufacturing technology, taking intelligent manufacturing as the main direction of the deep integration of the two technologies (ZHOU Ji, 2015); comprehensively promotes green manufacturing (2016) and strive to build an efficient, clean, low-carbon, recycling green manufacturing system. At the same time, from another point of view, the discipline group is a cluster of multiple disciplines that are closely linked, share resources and complement each other in function, and will form a discipline system composed of main disciplines, related 
disciplines, basic disciplines and emerging disciplines. The construction of advantageous characteristic subject group is the key to the characteristics of running a university. Only taking the construction of advantageous characteristic subject group as a breakthrough can we show the characteristics of the university and enhance its core competitiveness. In the future development and construction, the characteristic industry is still the key area of the construction and development of the advantageous characteristic discipline group. Focusing on the exchange and cooperation with the industry will become the key factor to promote the sustainable development of the advantageous characteristic discipline group.

As shown in Figure 2, the relationship between manufacturing industry and the advantageous and characteristic discipline group of iron and steel industry. With intelligent metallurgical equipment and green manufacturing as the main line and mechanical engineering as the main discipline, the advantageous characteristic discipline group integrates control science and Engineering, computer science and Technology, management science and Engineering and other supporting disciplines, and integrates vehicle engineering The disciplines of engineering, mining engineering and mathematics aim at the forefront of the world's metallurgical equipment science and technology development, combine modern science and technology with traditional metallurgical equipment technology, and carry out basic research and application basic research on the localization of advanced large-scale metallurgical equipment. In this advantageous and characteristic subject group, the eight research directions of intelligent metallurgical equipment manufacturing, metallurgical hydraulic equipment and system, green manufacturing process, robot and intelligent collaborative system, metallurgical process optimization control, intelligent sensor and equipment health monitoring, industrial Internet technology and system optimization and management decision-making are studied under the mutual integration of various disciplines to realize metallurgical equipment Transformation and upgrading will make our country make contribution from a large metallurgical equipment manufacturing country to a powerful country. Therefore, under the background of manufacturing industry, the dominant characteristic discipline group is positioned as the green steel intelligent equipment and system discipline group.

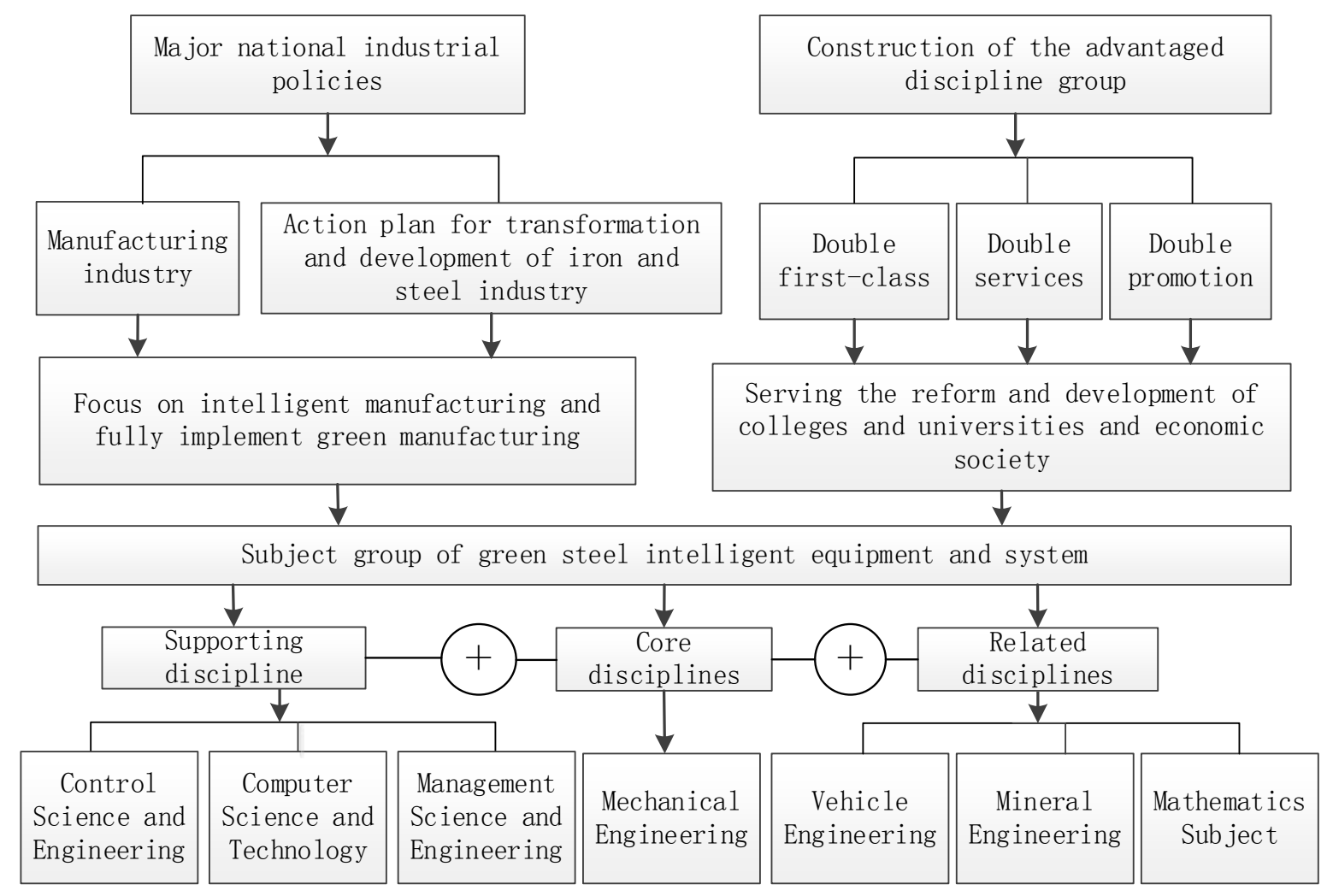

Figure 2. The relationship between manufacturing industry and the advantageous and characteristic subject group of iron and steel industry 


\section{Green Steel Intelligent Equipment and System Subject Group Construction Content}

The construction of advantageous characteristic discipline group is mainly carried out from four aspects: the improvement of discipline group conditions, the improvement of discipline group team, the improvement of discipline group innovation level and the improvement of discipline group education quality, as shown in Figure 3 is the construction system of advantageous characteristic discipline group. The construction of advantageous and characteristic subject groups is conducive to the optimization of subject structure, the cultivation of innovative talents, the promotion of collaborative innovation and the development of local economy and society.

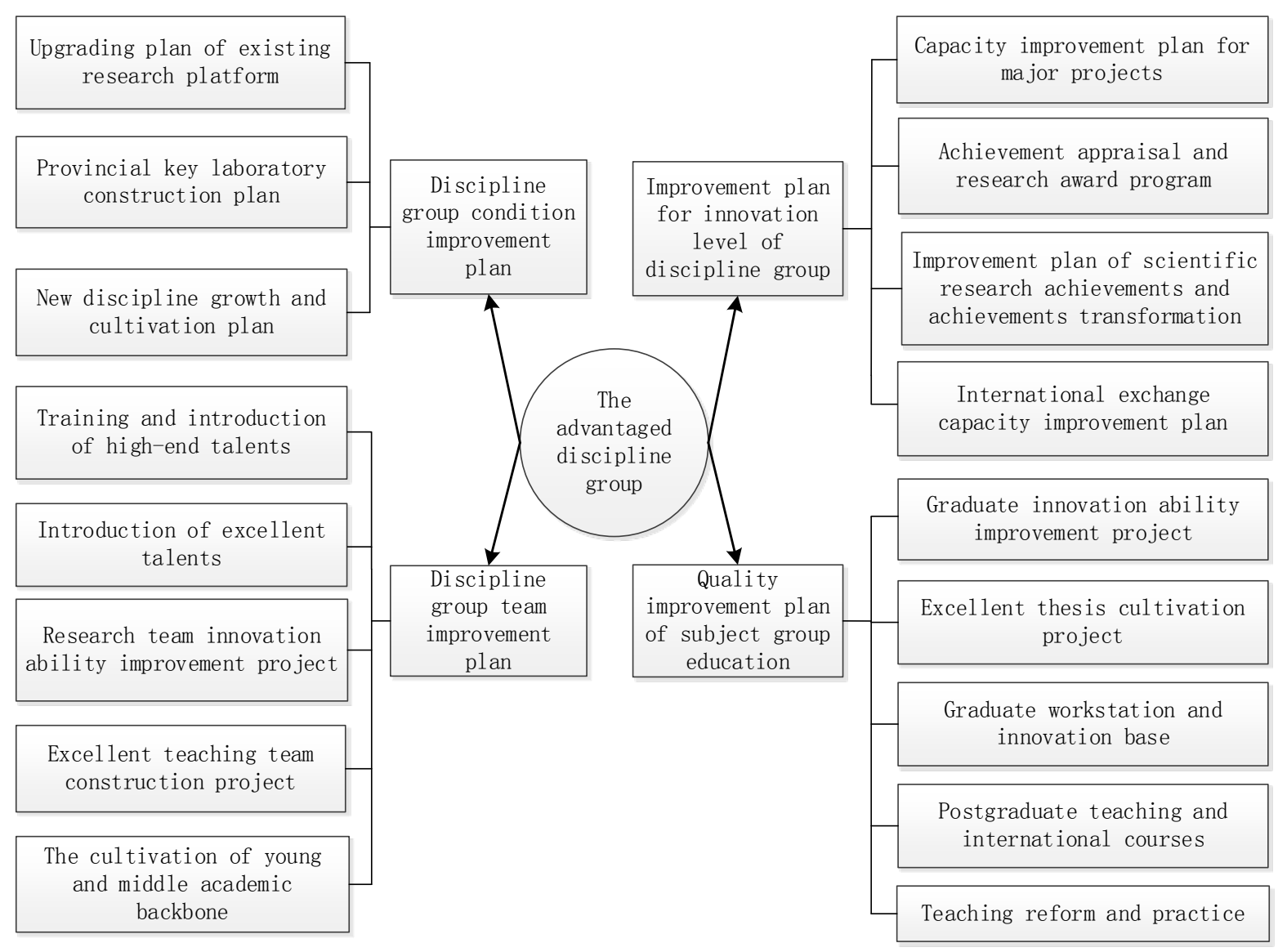

Figure 3. Construction system of subject group with advantages and characteristics

The research direction of the discipline group with advantages of green steel intelligent equipment and system is shown in Figure 4. Among them, the manufacturing direction of intelligent metallurgical equipment includes intelligent design and manufacturing of metallurgical equipment, advanced manufacturing of key parts of metallurgical equipment, mining equipment and mining vehicles, and on-line detection and system of surface defects based on machine vision; Metallurgical Hydraulic equipment and system includes research and development of high-speed and heavy-duty hydraulic servo components, rolling mill hydraulic AGC control and its test technology, hydraulic components and systems The green manufacturing process includes resource and environment attribute analysis of steel manufacturing system, green optimization control of steel manufacturing system and green integration technology of steel manufacturing system; robot and intelligent collaboration system includes multi-robot collaboration system, robot comprehensive perception and environment understanding, stability analysis and control design of intelligent system And state estimation; metallurgical process optimization control includes basic 
theory of complex industrial process control system, sensor network and network control system, intelligent modeling and control and optimization of metallurgical production process; intelligent sensor and equipment health monitoring includes on-line monitoring of mechanical equipment fault based on wireless sensor network, feature extraction of early weak fault of mechanical equipment, and active based Health monitoring method of sensing mechanical equipment and safety monitoring of metallurgical equipment; industrial Internet technology includes industrial hybrid cloud computing technology for complex mechanical manufacturing environment, data-driven intelligent information processing and mathematical modeling and Simulation in mechanical manufacturing process; system optimization and management decision include combination optimization and management decision, production system optimization and collaborative management and knowledge innovation engineering and information resource management.

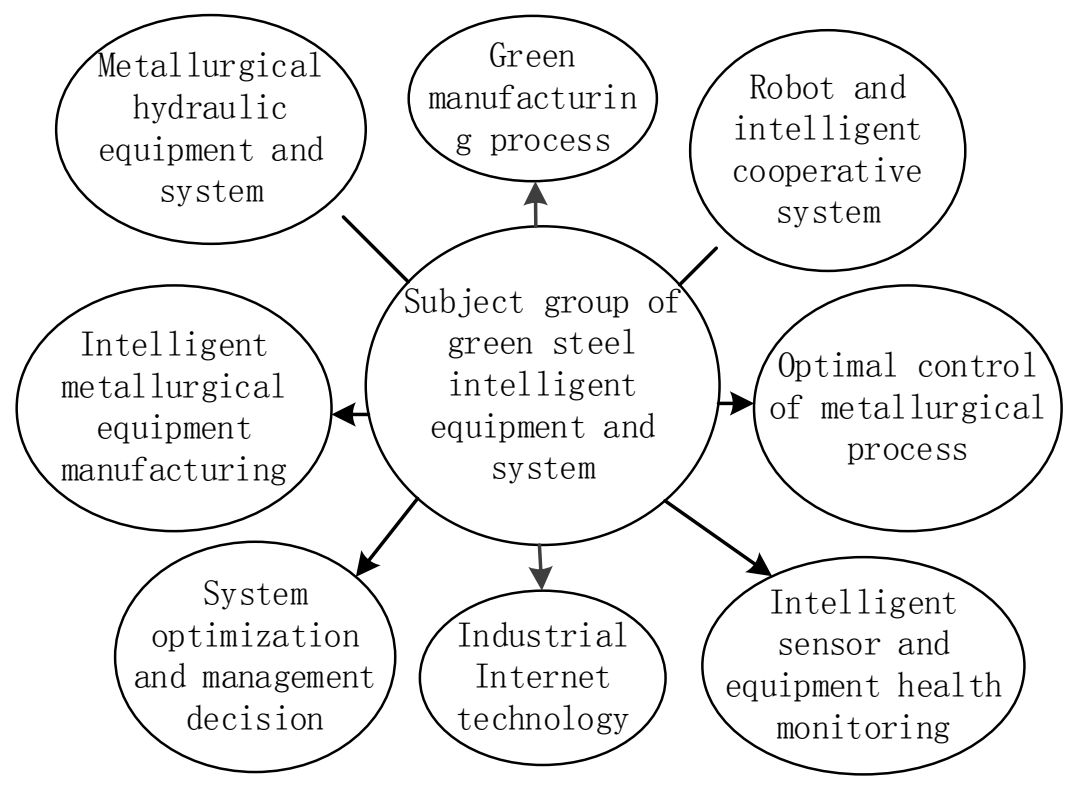

Figure 4. Research direction of green steel intelligent equipment and system subject group

\section{$5 \quad$ Main Measures for the Construction of Superior and Characteristic Discipline Groups}

(1) Innovate the mechanism of talent appointment and assessment, and promote the development of discipline group. We will open up special talent zones, establish a "competitive, fair and dynamic" employment mechanism, set posts according to objectives and tasks, adopt the responsibility Professor responsibility system.

(2) Integrate the resources of subject group and increase the investment of high-end instruments and equipment. We will build or expand the area of all kinds of key laboratories at all levels, integrate human, material and financial resources, build a discipline group innovation platform for overall management, rely on the development trend of high-end equipment manufacturing industry, invest in the purchase of high-end instruments and equipment for the development of the discipline group.

(3) We will increase the guarantee of the university's discipline group system, and actively introduce and cultivate all kinds of high-end talents. The discipline group has set up special talents introduction funds, and actively introduced high-level talents. We will strengthen the construction of post-doctoral mobile stations, select or introduce new young teachers from among the outstanding postdoctoral outbound students, employ experts and professors at home and abroad for academic exchanges every year.

(4) We should build a mechanism of collaborative innovation of discipline groups and strengthen the management and incentive mechanism of scientific research. With the help of manufacturing industry and 
other major industrial policies, we will jointly apply for the national key R \& D plan, key projects of NSFC and major projects with brother colleges and large national enterprises.

(5) We will improve the quality assessment of subject group education and promote the cultivation of innovative talents. Increase the degree thesis spot check, improve the classification quality evaluation and monitoring mechanism of graduate degree thesis, guide the classification training and quality evaluation.

(6) Give full play to the characteristics of metallurgical industry and strengthen the integration of production, learning and research of discipline groups. we will implement the mechanism of "sharing, co construction and win-win" production university research cooperation, further strengthen the in-depth cooperation with iron and steel enterprises, and systematize and base the scientific research, technological development and industrial development of the discipline group.

(7) Strengthen the construction of organizational system, and implement the responsibility system of discipline group leaders. We should give full play to the cohesion, influence and performance of academic leaders in the discipline group, formulate relevant incentive mechanisms and implement them in terms of teaching and scientific research according to different titles and tasks of teachers.

(8) Establish diversified incentive system and create a competitive atmosphere for discipline group construction. Strengthen a set of incentive mechanism for the development of disciplines, and promote the discipline of teachers in the discipline group.

(9) Consolidate the characteristics of discipline group and cultivate the interdisciplinary. According to the principle of relying on the industry characteristics and serving the regional economy, we should adhere to the development thinking of characteristics.

(10) Strengthen international exchanges and cooperation, and promote the popularity of discipline groups. Invite experts with international influence to cooperate and exchange with the university, host or jointly hold international academic conferences.

\section{Conclusions}

Facing the development of manufacturing industry and other major national industrial policies, relying on the characteristics of the industry, through a series of discipline construction systems and measures, to create distinctive characteristics of the dominant discipline group in the field of green steel intelligent equipment and systems, and finally build an important position integrating talents, disciplines and solving the major needs of metallurgical equipment. The characteristic subject group of green steel intelligent equipment and system advantages is of great significance to promote the construction of first-class university and first-class discipline, comprehensively improve the ability of university to serve the cultivation of talents and the development of economy and society, and vigorously promote the comprehensive reform of graduate education.

Acknowledgements. The research is funded by Provincial Teaching Research Project of Colleges and Universities in Hubei Province (2015233): Relying on the graduate workstation of Hubei province, exploring a new mode of mechanical graduate training.

\section{References}

1. http://www.gov.cn/gongbao/content/2015/content_2873744.htm

2. http://www.hubei.gov.cn/govfile/ezbf/201112/t20111209_1033791.shtml

3. YANG Zai-ming (2008), "The influence of the construction of university subject group on graduate education and the Countermeasures," Coal Higher Education, Vol.26, No.3, pp. 67-69.

4. MA Jian (2011). "Build a group of advantageous and characteristic disciplines and promote the construction of a high-level university," Science and Technology and Industrialization of Chinese Universities, No.3, pp. 22-24.

5. ZHOU Hai-yin (2015). "How does higher education adapt to "made in China 2025"," Journal of Shandong Normal University (Humanities and Social Sciences), Vol.60, No.4, pp. 119-124.

6. LI Tuo-yu, LI Fei and LU Guo-dong (2015). "Analysis on the way to improve the quality of Engineering Science and technology personnel training for "made in China 2025"," Research on Higher Engineering Education, No.6, pp. $17-23$. 
7. ZHOU Ji (2015). "Intelligent Manufacturing: the main direction of "made in China 2025"," China Mechanical Engineering, Vol.26, No.17, pp. 2273-2284.

8. http://www.miit.gov.cn/n1146285/n1146352/n3054355/n3057542/n3057545/c5253469/content.html 